Flammability and Sensitivity of Materials in Oxygen-Enriched Atmospheres

PAPER ID: STP-2015-0079

Available online at www.astm.org

\author{
Alfredo Juarez ${ }^{1}$, Susana A. Harper ${ }^{2}$, Horacio Perez ${ }^{3}$
}

\title{
Evaluation of Containment Boxes as a Fire Mitigation Method in Elevated Oxygen Conditions
}

\author{
REFERENCE: Juarez, A, Harper, Susana A., and Perez, Horacio, “Evaluation of Containment \\ Boxes as a Fire Mitigation Method in Elevated Oxygen Conditions,” 14th International Symposium \\ on Flammability and Sensitivity of Materials in Oxygen-Enriched Atmospheres, STP 1596, E. Davis \\ and T.A. Steinberg, Editors, STP-2015-0079, ASTM International, West Conshohocken, PA. 2016.
}

ABSTRACT: NASA performed testing to evaluate the efficacy of fire containment boxes without forced ventilation. Configurational flammability testing was performed on a simulation avionics box replicating critical design features and filled with materials possessing representative flammability characteristics. This paper discusses the box's ability, under simulated end-use conditions, to inhibit the propagation of combustion to surrounding materials. Analysis was also performed to evaluate the potential for the fire containment box to serve as an overheat/ignition source to temperature sensitive equipment (such as items with lithium-ion batteries). Unrealistically severe combustion scenarios were used as a means to better understand the fire containment mechanism. These scenarios were achieved by utilizing materials/fuels not typically used in space vehicles due to flammability concerns. Oxygen depletion, during combustion within the fire containment boxes, drove self-extinguishment and proved an effective method of fire containment.

Keywords: Avionics box, configuration flammability, gaseous oxygen, liquid solvents, volatility

\footnotetext{
1 Standard Test Lead Flammability Test Engineer, Jacobs Engineering, White Sands Test Facility, Las Cruces, New Mexico 88012

2 Standard Test Project Manager, National Aeronautics and Space Administration, White Sands Test Facility/RF111, Las Cruces, New Mexico 88012

3 Materials and Processing, Lockheed Martin, Johnson Space Center, Houston, Texas 77058
} 


\section{Background}

Flight avionics boxes are used with a wide range of applications throughout the International Space Station (ISS) cabin. Avionics boxes are an efficient means of containing required materials within an enclosure. Beyond the specific avionics box application, containment boxes may also be considered as a potential strategy for isolating possible flammable materials in general.

NASA performed testing to evaluate the efficacy of fire containment boxes without forced ventilation. Configurational flammability testing was performed on a simulation avionics box replicating critical design features and filled with materials possessing representative flammability characteristics. This paper discusses the box's ability, under simulated end-use conditions, to inhibit the propagation of combustion to surrounding materials. Analysis was also performed to evaluate the potential for the fire containment box to serve as an overheat/ignition source to temperature sensitive equipment (such as items with lithium-ion (Li-Ion) batteries) as well as to evaluate general flame propagation potential to nearby flammable materials. Unrealistically severe combustion scenarios were used as a means to better understand the fire containment mechanism. These scenarios were achieved by utilizing materials/fuels not typically used in space vehicles due to flammability concerns.

\section{Simulated Avionics Box Test Methodology}

NASA White Sands Test Facility (WSTF) routinely performs NASA Standard 6001 Upward Propagation (Test 1) to qualify prospective materials, with respect to flammability, for final use 
on spacecraft. NASA Standard Test 1 evaluates a material's ability to self-extinguish a flame within a 6-in. vertical burn path for a given pressure and oxygen concentration [1]. Open flame ignition is initiated by the application of an electrical current to a helically formed bare 20 gauge nickel chromium wire wound around a chemical igniter, which in turn applies an open flame of known energy output to the sample for approximately 25 seconds. Radiant heat ignition utilizes the same electrical circuit but omits the NASA-STD-6001 igniter.

This upward propagation test methodology provided the perfect test bed for simulating a combustion event within an avionics box. Precise placement of an overwhelming ignition source provided control over which materials were ignited. Temperature measurements could be obtained at key locations to verify ignition of test materials and offer insight into the method of extinguishment as well as the overheat potential of the enclosure. Flammable poly methylmethacrylate (PMMA) witness plates were placed above the enclosure feed-through holes to evaluate the propensity of escaping flames to ignite nearby materials. All testing was performed within a $1.4 \mathrm{~m}^{3}\left(50 \mathrm{ft}^{3}\right)$ flammability chamber.

\section{Scope of Testing}

The objective of this test was to mimic a fire occurring in an avionics box in the projected conditions present on future spacecraft. Testing was performed to assess the potential for breach of enclosure (the avionics box) in the event of a fire within the enclosure, assuming normal operating conditions. Not only was the test article evaluated, but also the general containment approach was evaluated as a tool for inhibiting fire propagation both directly and as a potential overheat ignition source. All testing was performed in worst-case planned end use environmental 
conditions of 40 percent oxygen and $101.3 \mathrm{kPa}$ (14.7 psia) pressure. Pressure and oxygen concentration were achieved by first pulling vacuum on the test chamber, followed by backfilling the pre-mixed gas to ensure uniform oxygen concentrations throughout, including within the simulation avionics box. Approximately 15 min elapsed between achieving the test atmosphere and onset of testing to ensure adequate mixing of gases and 'soaking' of any porous materials prior to testing.

Testing was divided into two portions: 1) realistic simulation of current ISS avionics box configuration, and 2) creation of unrealistically severe combustion events. Both scenarios utilized the same simulation enclosure.

\section{Test Article}

Instead of using an actual avionics box, a simplified model consisting of a welded 6016 aluminum box was constructed and used as the test article. All box design parameters were intended to emulate worst-case flammability conditions on current avionics box designs to ensure testing appropriately modeled worst-case heat transfer, flame escape, and propagation to adjacent material. To best represent end use configuration, the lid was bolted to the enclosure using a bolt spacing of less than $31.75 \mathrm{~mm}$ (1.25 in.). The model avionics box used a representative volume of $15.14 \mathrm{~L}\left(923.4 \mathrm{in}^{3}\right)$. The base had a length and width of 24 by $24 \mathrm{~cm}$ (9 by 9 in.), with a height of $29 \mathrm{~cm}$ (11.4 in.). For current avionics box designs, the worst-case (thinnest cross-section) wall thickness is $0.38 \mathrm{~cm}(0.150 \mathrm{in}$.$) . This test used a conservative wall$ thickness of $\sim 0.25 \mathrm{~cm}$ ( $0.1 \mathrm{in}$.). The thinner wall thickness allowed conservative modeling of 
surface temperatures. Surface temperature modeling was used to estimate the potential for heat generated within the box to serve as an ignition source to adjacent materials.

An important facet to testing was to assess any flames that could potentially escape the box and propagate to surrounding materials. Printed circuit board (PCB) internal pass-through connector slots and vents were identified as potential flame escape pathways and were included in the representative avionics box test model. Slots were cut into the lid of the avionics box to allow PCB internal pass-through connectors to protrude through the enclosure. To ensure the test was conservative, the pass-through connectors were not sealed, to allow respiration of the box due to pressure fluctuations caused by combustion. All tests were performed with the enclosure cover facing upward to promote combustion and exploit buoyancy in $1 \mathrm{~g}$ conditions by utilizing the PCB internal pass-through connector portholes. Flammable materials (PMMA) were placed above the box to evaluate whether any escaped flames could induce ignition and propagation. Upward orientation was chosen as a worst-case condition with respect to flame escape scenarios.

A simplified vent fixture utilizing a "tortuous path” for venting gas was implemented to emulate flight conditions without overcomplicating fabrication or assembly. A vent assembly was located on the side of the box to model planned use configuration with machined windows similar to flight models. The avionics box test article is shown in Fig. 1.

Three surface mount thermocouples acquired temperature data to assess the heat damage potential of a combustion event occurring within an avionics box. One thermocouple was located on the outside cover directly above the ignition source, and the other two thermocouples were located on the inner and outer surfaces of the vent fixture.

\section{Realistic Simulation Test Parameters}


Simulation testing entailed use of representative end-use materials (wiring, circuit boards, insulation material, etc.). Added severity was achieved by the use of materials known to be more flammable than anticipated flight materials.

Six rows of commercial off-the-shelf (COTS) Arathane ${ }^{\circledR 1}$-coated PCBs were bolted to the lid of the test box to mimic a flight array. Seven lengths of 20-strand 20-gauge polytetrafluoroethylene (PTFE) coated silver-clad copper wires were restrained within the avionics box by four silicone-clad stainless steel P-clamps located $2.5 \mathrm{~cm}$ (1 in.) apart to mimic planned spacing in future box designs. The PTFE wire bundle was woven through the PCBs to provide a propagation path. Six nylon zip ties held the wires together, spaced $5.1 \mathrm{~cm}$ (2 in.) apart on wires to serve as fuel within the enclosure (Fig. 2). Nylon and PTFE are typical materials used in flight configuration and therefore represent a realistic scenario.

A 91 by $7.6 \mathrm{~cm}$ (36 by 3 in.) polyvinylchloride (PVC) ribbon cable was woven through the PCBs to create a realistic configuration and provide fuel within the enclosure. Per maximum oxygen concentration (MOC), use of the more flammable PVC is conservative over the polyimide material normally used in flight configurations (MOC PvC $_{2} \sim 40 \%$; MOCPolyimide $_{\text {P }}$ $>99 \%$ ) [2,3]. Commercial off-the-shelf items that included mezzanine connectors were used for PVC cable. Figure 2 shows the final placement of materials attached to the interior of the enclosure. Components are labeled as follows: 1) vent fixture; 2) nylon tie wrap; 3) PTFE wire strands, and 4) P-clamps.

Finally, four 1.6 by 15.2 by $6.4 \mathrm{~cm}(0.625$ by 6 by 2.5 in.) blocks of highly flammable polyurethane foam $(\mathrm{MOC}=19 \%)$ [4] were placed between some of the PCBs to add conservatism to the test. Commercial off-the-shelf PCB internal pass-through connectors were

1 Arathane $^{\circledR}$ is a registered trademark of Ciba-Geigy Corporation, Tarrytown, New York. 
used for testing (Fig. 3). As a COTS item, PCB internal pass-through connectors were thought to be made of phthalate; however, chemical verification was not performed. The connectors were located on the lid of the enclosure without sealing, to allow for gas exchange.

Figure 4 shows the final placement of materials within the enclosure. Each component is labeled as follows: 1 ) realistic igniter position 1 ; 2) realistic igniter position 2; 3) COTS ribbon cable mezzanine connectors; 4) COTS PVC ribbon cable; 5) polyurethane foam slabs; and 6) COTS Arathane-coated PCB.

Tests performed using realistic materials were ignited with NASA-STD-6001 Flammability Test 1 standard chemical igniters [1]. Igniters were located $\sim 0.64 \mathrm{~cm}(0.25$ in.) below the bottom edges of the materials chosen as ignition points. Figure 4 shows the positioning of the two igniter coils. Test 1 and Test 2 are indicated by igniter positions 1 and 2, respectively. Test 1 of the realistic scenario tests was ignited $0.64 \mathrm{~cm}(0.25$ in.) below a ribbon cable connector. Test 2 of the realistic scenario tests was ignited $0.64 \mathrm{~cm}(0.25 \mathrm{in}$.) below two of the polyurethane foam blocks. Figure 4 shows the final placement of all materials within the enclosure just prior to attaching the lid.

No fans were used inside the modeled avionics box. Current avionics box designs use heat exchangers for cooling.

\section{Unrealistically Severe Test Parameters}

The unrealistically severe scenario utilized the highly flammable polyurethane foam as a fuel and nothing more. The PCBs were stripped of the mounting surfaces, and copper mounting fixtures were used to attach the foam blocks to the avionics box (Fig. 5). These blocks were mounted to 
the avionics box directly under the PCB internal pass-through connectors, which were left on the test article to obtain a direct comparison between realistic and worst-case test scenarios with respect to leak paths and flame escape routes.

Testing was performed with two packing densities: 60 and 80 percent free volume. The freevolume density was achieved by varying the width of the polyurethane foam blocks. For these tests, the gas contained within the foam itself was disregarded and the volume of the foam was calculated by simply multiplying the three geometric dimensions. Gaps were purposely left between rows of foam to encourage propagation.

Because of the numerous chemical igniters needed to ignite the various foam blocks simultaneously, concerns with respect to oxygen consumption arose. These concerns led to the use of hot-wire igniters for the foam worst-case scenario testing. Ignition of the foam blocks was obtained by supplying an electrical current to six helically wound 20 gauge nickel chromium wires $\sim 2.5 \mathrm{~cm}(1 \mathrm{in}$.$) across. Each of these six igniter coils made contact with two of the foam$ blocks to ensure ignition. Figure 6 shows the positioning of the six igniter coils at the bottom of the enclosure.

\section{Test Results}

Ignition of materials within the simulation avionics box was verified prior to the performance of any in-depth posttest analysis. Table 1 displays the pre- and posttest oxygen and carbon dioxide concentrations within the test chamber. Pre- and posttest mass quantities represent the sum of all available flammable material within the avionics box. Secondary verification of ignition and combustion was observed using test videos. Smoke emanating from the enclosure confirmed 
combustion occurring within the container. Peak temperatures were consistently measured at the thermocouple located on the avionics box cover directly above the ignition points.

Ignition of the first realistic scenario test was initiated beneath the ribbon cable mezzanine connector. Combustion propagated to the ribbon cable, P-clamp/PTFE-coated wire bundle, and the foam blocks directly above the ignition source. The foam blocks located on the opposite end of the enclosure were not involved in this combustion event. Peak surface avionics box cover temperature was measured at $68^{\circ} \mathrm{C}\left(155^{\circ} \mathrm{F}\right)$. Smoke was seen emanating from the test enclosure via test video.

The second realistic scenario yielded similar results. Combustion was initiated at the foam blocks, and propagation proceeded halfway up the blocks and quickly extinguished. Peak avionics box cover temperatures were recorded at approximately $66^{\circ} \mathrm{C}\left(150^{\circ} \mathrm{F}\right)$. Smoke was observed escaping the enclosure through the pass-through holes; however, no flames were observed.

For the two unrealistically severe scenarios, self-extinguishment of the foam blocks used to create the 60 and 80 percent free-volume tests occurred despite ignition of each of the blocks. Propagation did not even extend the entire length of the foam blocks. Clean, uncharred surfaces remained post free-volume tests. Peak temperatures recorded at the avionics box lid were $52{ }^{\circ} \mathrm{C}$ $\left(125^{\circ} \mathrm{F}\right)$ and $104^{\circ} \mathrm{C}\left(220^{\circ} \mathrm{F}\right)$ for 60 and 80 percent free volume, respectively. In both cases, peak temperatures lasted less than $2 \mathrm{~s}$. The higher temperatures obtained in these last two scenarios indicate that the initial increased free volume, and therefore an increased amount of available oxygen at the time of ignition, resulted in the most severe scenario observed during this evaluation. Despite the severe test conditions, self-extinguishment of the test material was observed. 


\section{Conclusions}

Configurational flammability testing performed on a simulation avionics box yielded results unique to this type of assembly that may also be considered as a potential strategy for isolating other possible flammable materials and components in spacecraft vehicles. Analysis was performed to evaluate the potential for the fire containment box to serve as an overheat/ignition source to temperature sensitive equipment (such as items with Li-Ion batteries) as well as the ability of escaping flames to propagate to nearby materials. Unrealistically severe combustion scenarios were also used as a means to better understand the fire containment mechanism. Oxygen depletion, during combustion within the fire containment boxes, drove self-extinguishment and proved an effective method of fire containment.

In all test scenarios, realistic as well as unrealistically severe polyurethane foam testing, selfextinguishment of materials was observed. As polyurethane is known to be highly flammable at the 40 percent oxygen and $101.3 \mathrm{kPa}$ (14.7 psia) test conditions [4], it is particularly noteworthy that in all tests polyurethane at some point ignited and self-extinguished. Premixed gas was supplied to the test chamber after pulling vacuum, guaranteeing the interior of the box had fully mixed 40 percent oxygen available at the initiation of the test. It is believed that, in all cases, self-extinguishment is due to oxygen depletion occurring inside the avionics box as a result of combustion. Though the simulation avionics box was not hermetically sealed and various known leak paths existed, it was shown that positive pressure due to gas expansion and combustion products inhibits fresh oxygen from replenishing the constrained volume until self-extinguishment occurs. 
Although smoke was observed exiting the avionics box from around the PCB internal pass-through connector interfaces, no flames were observed; therefore, no direct propagation risks to nearby materials were noted. Surface temperature data were analyzed to assess the potential of the avionics box serving as an overheat source to surrounding temperature-sensitive equipment (such as items with Li-Ion batteries). The highest temperature obtained for any of the tests was $104^{\circ} \mathrm{C}\left(220^{\circ} \mathrm{F}\right)$, and it was only sustained for a couple of seconds before self-extinguishment occurred, after which temperatures quickly dropped. Since this short-lived high temperature was obtained with an unrealistically high 80-percent free volume resulting in a significantly higher quantity of oxygen available for combustion, these conditions are unlikely to occur in actual use conditions. Maximum temperatures obtained, coupled with short duration temperature increases, indicate an avionics box or similar fire containment box is not a likely overheat ignition source for nearby temperature sensitive equipment.

It should be noted that all of the testing and results presented here were performed for containment boxes without forced air convection. These data should not be applied to units containing forced air convection. Additional testing would need to be performed to assess flammability risks of similar systems with the use of forced air convection.

\section{Acknowledgements}

The authors would like to acknowledge the test team's hard work in the production of the test data: John Bouvet and Steve Bailey; WSTF Machinist, John Cervoni, for his fabrication of the vent fixture; and Richard $\mathrm{C}$ de Baca for his work in the coordination and implementation of the test fixture. 


\section{References}

[1] NASA-STD-6001B, Flammability, Offgassing, and Compatibility Requirements and Test Procedures, Test 1, “Upward Flame Propagation,” National Aeronautics and Space Administration, Washington, DC, August 2011.

[2] Hirsch, D.B., Juarez, A., Peyton, G.J., Harper, S.A., and Olson, S.L., "Selected Parametric Effects on Materials Flammability Limits,” $41^{\text {st }}$ International Conference on Environmental Systems, Portland, July 2011.

[3] Hirsh, D.B., Williams, J.H., Harper, S.A., Beeson, H.D., and Pedley, M.D., “Oxygen Concentration Flammability Thresholds of Selected Aerospace Materials Considered for the Constellation Program," $2^{\text {nd }}$ International Association for the Advancement of Space Safety Conference, Chicago 2007.

[4] Harper, S.A., Hirsch, D.B., and Smith, S., "Determination of Time Required for Materials Exposed to Oxygen to Return to Reduced Flammability,” Journal of ASTM International, 6.10 (2009): 1-11. 


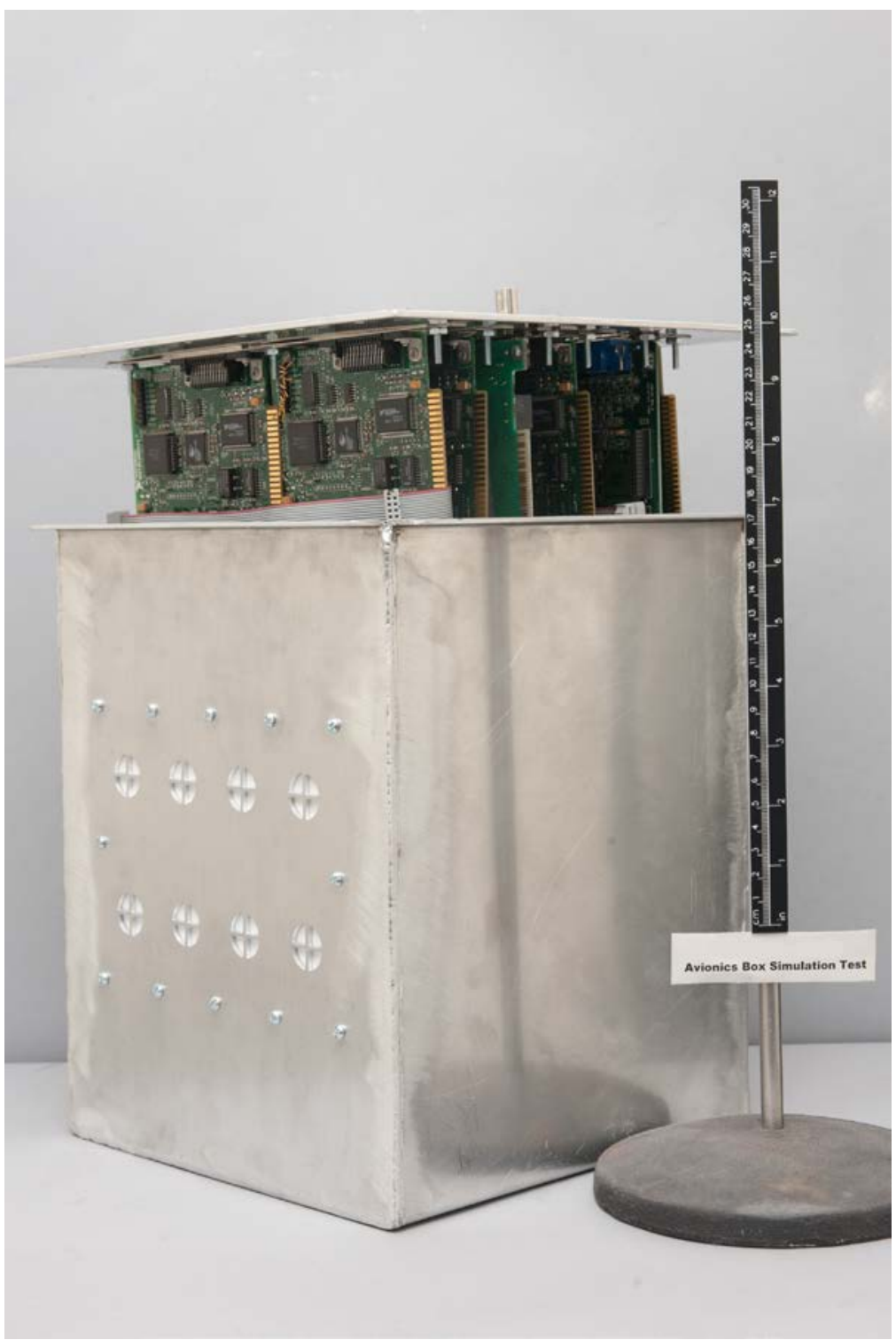

FIG. 1-Avionics box - vents and PCBs. 


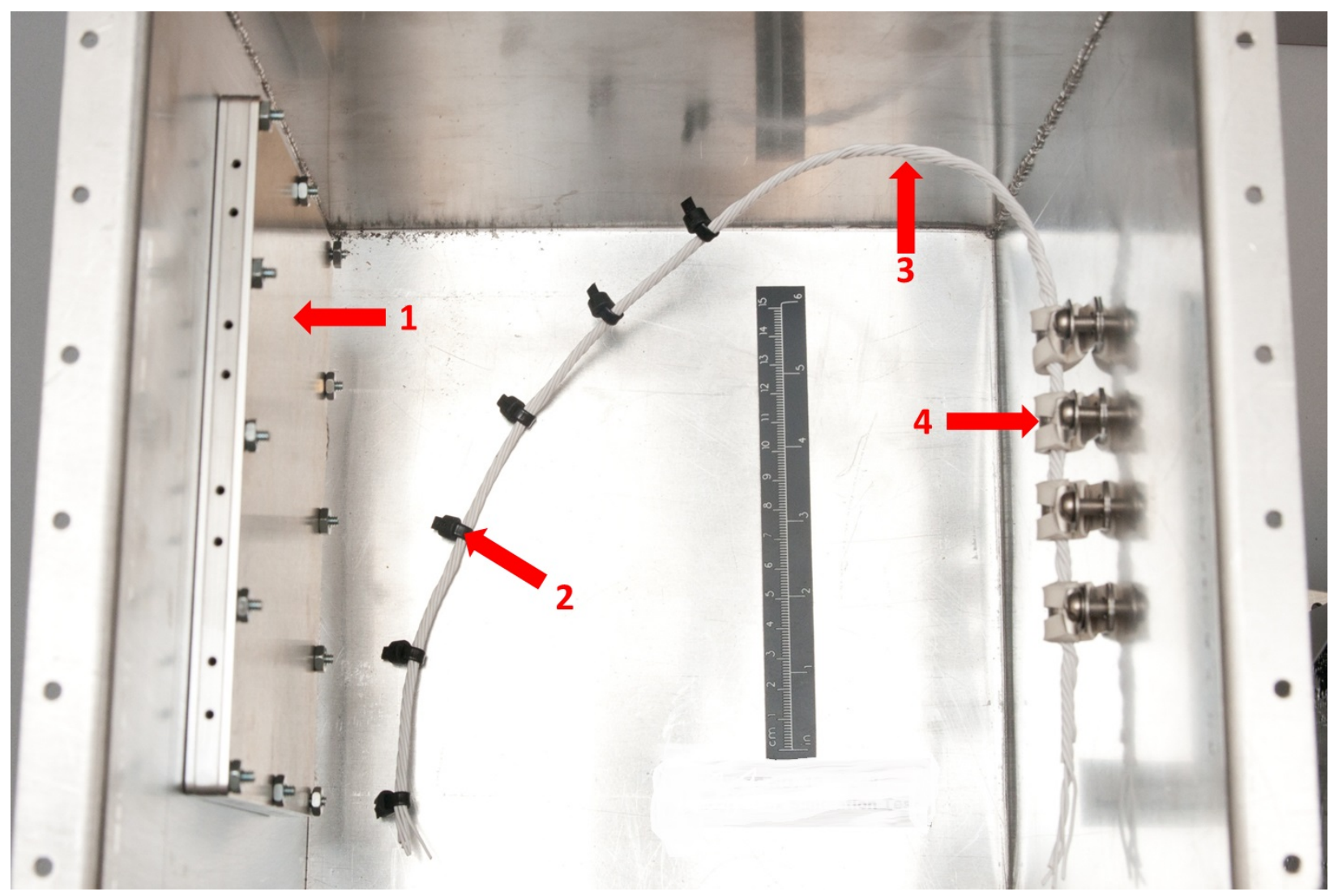

FIG. 2-Inside of simulation avionics box, showing 1) vent fixture; 2) nylon tie wrap; 3) PTFE wire strands; and 4) P-clamps. 


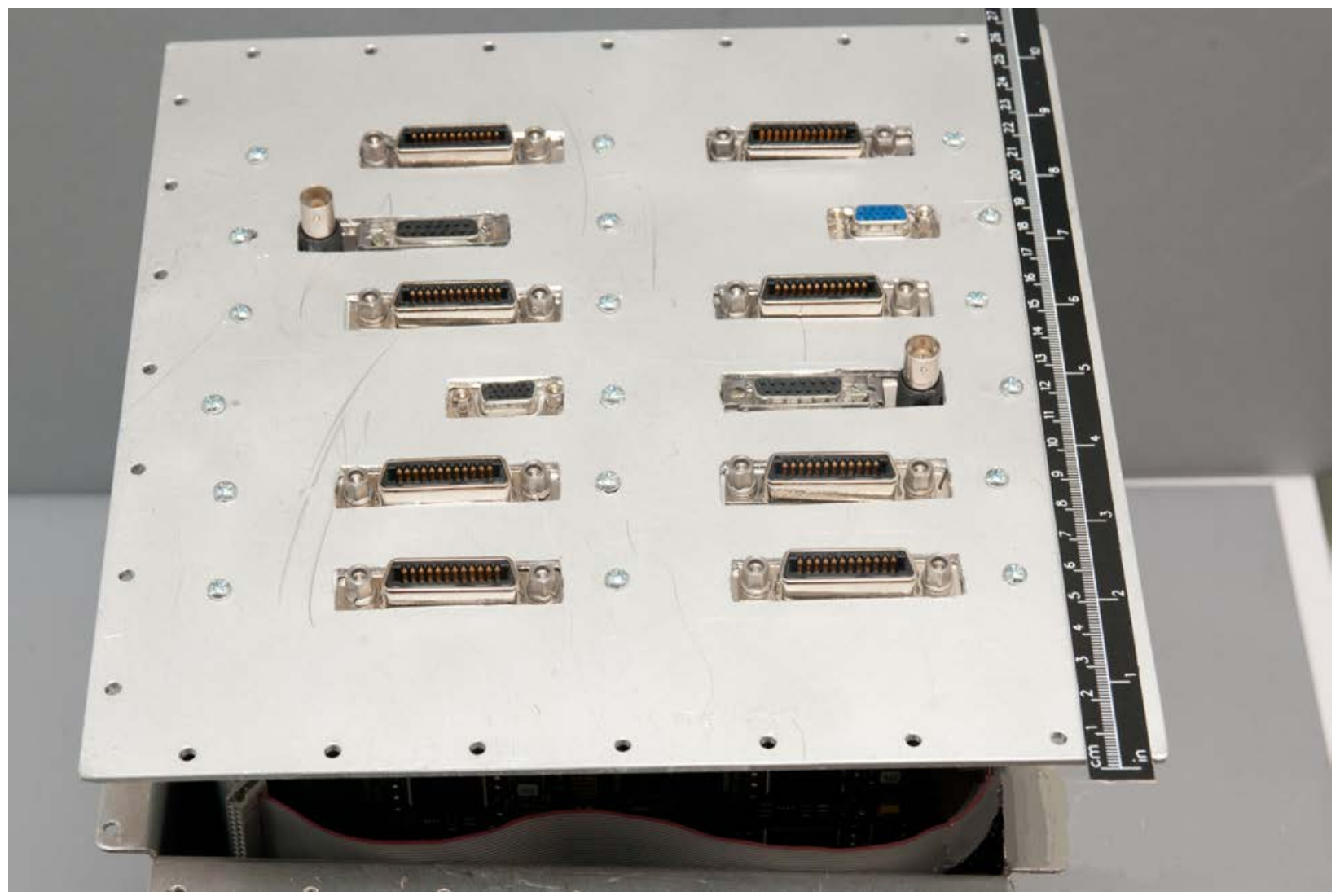

FIG. 3-Avionics box lid with PCB internal pass-through connectors. 


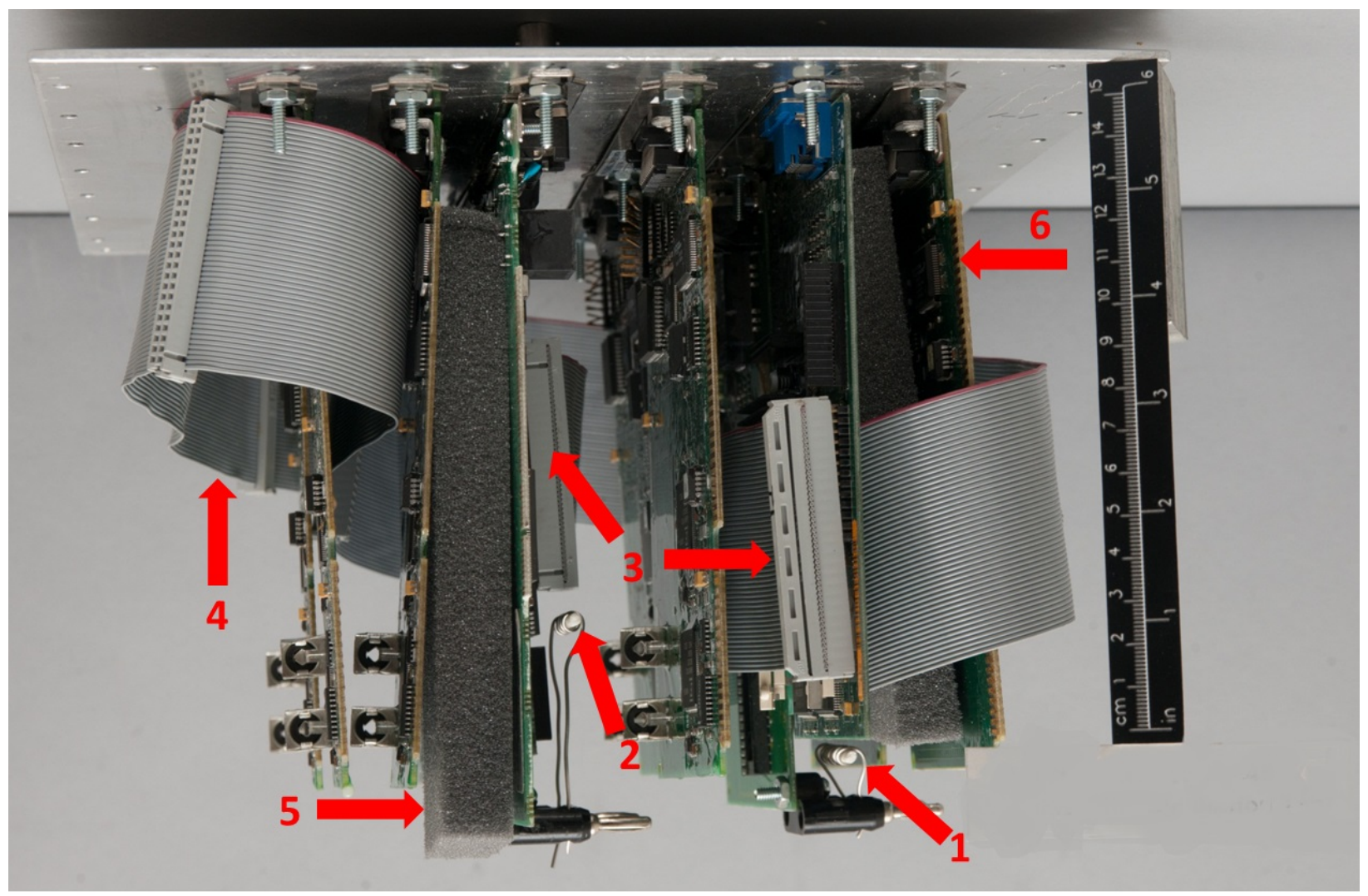

FIG. 4-Simulation avionics box test materials final placement, including 1) realistic igniter position 1 ; 2) realistic igniter position 2; 3) COTS ribbon cable mezzanine connectors; 4) COTS PVC ribbon cable; 5) polyurethane foam slabs; and 6) COTS Arathane-coated PCB. 


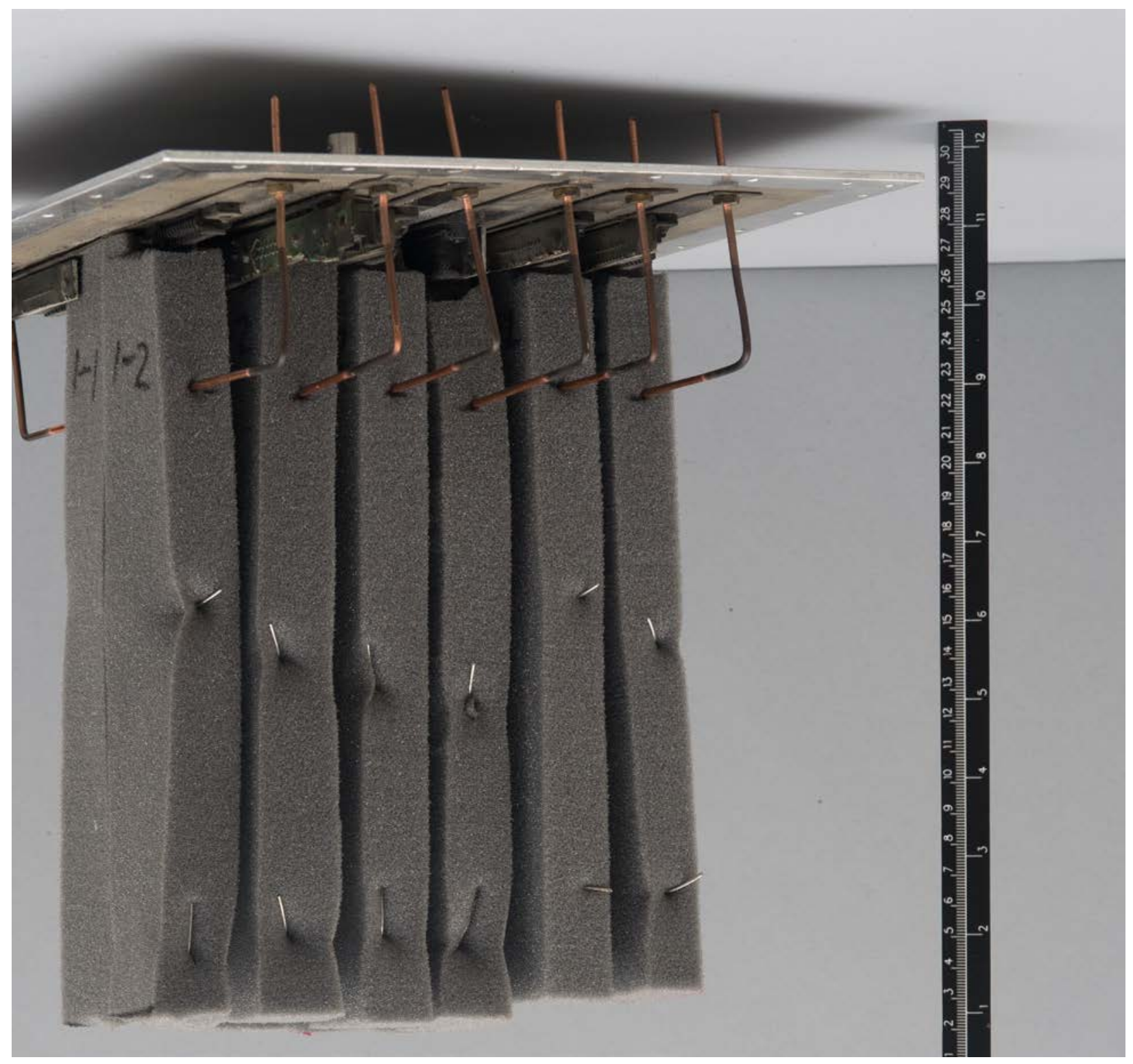

FIG. 5-Mounted polyurethane foam. 


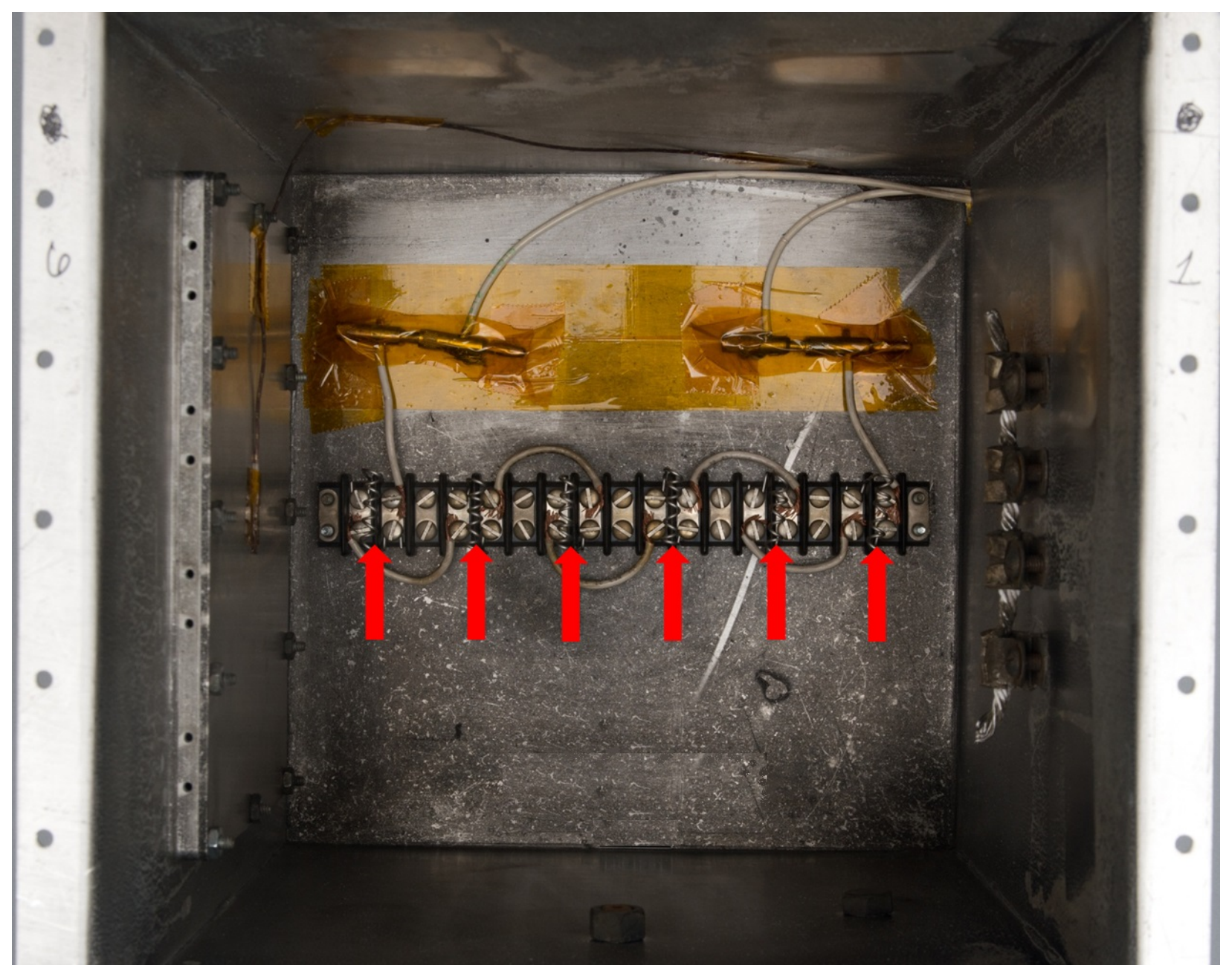

FIG 6-Hot wire igniter fixture showing placement of the six igniter coils. 
Table 1-Pre- and posttest oxygen and carbon dioxide concentrations and mass of materials.

\begin{tabular}{l|ccc|ccc|ccc}
\hline & \multicolumn{3}{|c|}{ Pretest } & \multicolumn{3}{c|}{ Posttest } & \multicolumn{3}{c}{ Posttest Deltas } \\
\cline { 2 - 10 } & $\begin{array}{c}\mathrm{O}_{2} \\
\text { (\% vol.) }\end{array}$ & $\begin{array}{c}\text { Mass } \\
\text { (grams) }\end{array}$ & $\begin{array}{c}\mathrm{CO}_{2} \\
\text { (\% vol.) }\end{array}$ & $\begin{array}{c}\mathrm{O}_{2} \\
\text { (\% vol.) }\end{array}$ & $\begin{array}{c}\text { Mass } \\
\text { (grams) }\end{array}$ & $\begin{array}{c}\mathrm{CO}_{2} \\
\text { (\% vol.) }\end{array}$ & $\begin{array}{c}\mathrm{O}_{2} \\
\text { (\% vol.) }\end{array}$ & $\begin{array}{c}\text { Mass } \\
\text { (grams) }\end{array}$ & $\begin{array}{c}\mathrm{CO} \\
\text { (\% vol. })\end{array}$ \\
\hline Realistic Scenario 1 & 40.10 & 246.66 & 0.00 & 39.90 & 240.89 & 0.08 & -0.20 & -5.77 & 0.08 \\
$\begin{array}{l}\text { Realistic Scenario 2 } \\
\text { 60 Percent Free }\end{array}$ & 40.15 & 240.89 & 0.00 & 40.02 & 234.04 & 0.08 & -0.13 & -6.85 & 0.08 \\
$\begin{array}{l}\text { Volume } \\
\text { 80 Percent Free }\end{array}$ & 40.30 & 189.63 & 0.00 & 40.10 & 185.92 & 0.08 & -0.20 & -3.71 & 0.08 \\
Volume & 40.30 & 96.89 & 0.00 & 40.10 & 92.03 & 0.08 & -0.20 & -4.86 & 0.08 \\
\hline
\end{tabular}

